

\title{
Olfacto-protective roles of Nigella sativa oil in Harmaline- induced essential tremor modelling Folarin $R^{*}$, John S, Oyenuga O, Tijani N, Otulana O, Mbonu E
}

${ }^{1}$ Neurophytotherapy Research Unit, Department of Anatomy, Olabisi Onabanjo University, Sagamu, Nigeria.

*Correspondence: Dr R Folarin, Neurophytotherapy Research Unit, Department of Anatomy, Olabisi Onabanjo University, Sagamu, Nigeria. Email:royhaan.folarin@oouagoiwoye.edu.ng;

ORCID - https://orcid.org/0000-0003-1558-6158.

\begin{abstract}
Background: Harmaline is a tremorgenic beta-carboline, reported to induce acute postural and kinetic tremor. Essential Tremor (ET) is an idiopathic slowly neurodegenerative tremor disorder which also compromises olfactory acuity. Nigella sativa (NS) is a therapeutic agent widely used in the treatment of various ailments. Objective: To determine the effect of NSon olfactory functions of mice treated with harmaline.

Methods: Seventy-five BALB/c male mice weighing 20g-25g, were equally divided into five groups, namely CNTRL (received only Normal saline), NS (received NS oil1ml/kg), HML(received Harmaline 20mg/kg), HNS (received Harmaline and Nigella sativa concurrently), and NSH (received NSfollowed by Harmaline). Olfactory sensitivity and discrimination were assayed through buried food test. The olfactory bulb was assayed neurochemically for glutamate and dopamine, and histologically for neuronal architecture using haematoxylin and eosin stain. Differences in neurochemical and histological data, body weight, appetite, relative brain weight, sensitivity and discrimination indices were statistically analysed.

Results: NS was significantly protective against the negative effects of Harmaline. It also effected quick olfactory discrimination, increased dopamine level, decrease in weight difference and increased food consumption in the animals. However, Harmaline increased relative brain weight and GPX levels. The concurrent administration aided in the reduction of neuronal density while neuronal average size reduced on pre-treatment with NS.

Conclusion: Harmaline did not induce tremor in the animals, though it resulted in histological and neurochemical deficits. However, it resulted in olfactory insensitivity and indiscrimination, both of which were prevented and ameliorated by Nigella sativa oil.
\end{abstract}

Keyword: Appetite, Brain weight, Dopamine, Essential tremor, Harmaline, Nigella sativa, Olfaction.

\section{Introduction}

Tremor is an involuntary rhythmic movement of a body part with a relatively constant frequency but variable amplitude. It is caused by alternating contractions of antagonistic muscles.
Tremor is the most common of all movement disorders, while essential tremor (ET) is the most common neurologic cause of postural or action tremor. ${ }^{[1]}$ It usually presents as a bilateral, postural $(6$ to $12 \mathrm{~Hz}$ ) tremor of the hands, followed by a kinetic and resting component. 
The upper limbs are often symmetrically involved, but with disease progression, the head and voice (and less commonly legs, jaw, face, and trunk) may be involved. [2]. Though it has a benign effect on life expectancy, ET could be a source of embarrassment and serious disability to a small percentage of patients. The symptoms are typically progressive and potentially disabling, as it often forces the patients to change jobs or seek early retirement. [3]

While some earlier reports described olfactory deficitsin patients with ET, even though often milder than what obtains in Parkinson's disease, ${ }^{[4]}$, some relatively recent studies found no correlation between ET and olfactory dysfunctions. ${ }^{[5]}$ However, being the only part of the nervous system with direct contact with the external environment, the olfactory system remains a vital system to living organisms; in mammals, it consists of special structural characteristics such as the olfactory epithelium, olfactory mucosa, and olfactory plate.

Harmaline $\left(\mathrm{C}_{14} \mathrm{H}_{13} \mathrm{~N}_{2} \mathrm{O}\right)$ and harmine are tremorgenic $\beta$-carbolines that, on the administration to experimental animals, induce an acute postural and kinetic tremor of the axial and truncal musculature. This drug-induced action tremor has been proposed as a model of ET. [6]Harmaline induces action tremor in mammals, and as an easily elicited model, it has attracted increasing interests from workers searching for new therapies for ET. Oxidation of harmaline is accompanied by the loss of water which effectively generates harmine, while harmane and harmalolare the other $\beta$-carboline alkaloids.

Individuals with ET have higher blood levels of harmane, especially in familial cases, [7] which are not due to higher dietary intake. Higher levels of olfactory dysfunction, measured with smell identification deficiencies, has been correlated with high harmane levels in the blood of ET patients. ${ }^{[8]}$ Harmane in high doses may cause tremor, [6] or do so via a metabolite, harmine, but its role could also be from tissue damage that gives rise to tremor.

Nigella sativa, a family of Ranunculaceae, is a widely used medicinal plant across the world. The seeds of Nigella sativa have remained important to the Unani and Ayurvedic systems of medicine, and have been used in the treatment of various ailments such as skin diseases, jaundice, gastrointestinal disorders, anorexia, conjunctivitis, dyspepsia, rheumatism, diabetes mellitus, hypertension, paralysis, amenorrhoea, asthma, bronchitis, headache, flu and eczema. [9]

As the search for novel and alternative therapies to neurological disorders remain relevant to ET, Nigella sativa oil was employed and investigated in this study for its protective potentials on the olfactory properties of BALB/C (albino) mice with induced ET through subcutaneous administration of harmaline. These properties were assessed on the olfactory bulbs of the mice histologically with haematoxylin and eosin (H\&E) staining, neurochemically with spectrophotometric quantification of glutamate and dopamine; and neurobehaviourallywith the measurement of olfactory sensitivity and discrimination using the buried food test.

\section{Methods}

Acquisition of research materials

BALB/c mice (used for this study) are in-bred albino mice strain, most widely used in animal experimentations for their immunodeficient and thus highly sensitive nature to experimental manipulations. Seventy-five (75) male BALB/c mice weighing $15 \mathrm{~g}-30 \mathrm{~g}$, were acquired from a reliable source and distributed equally into five groups, namely CNTRL, HML, NS,HNS, and NSH.The animals were housed in respective 
well ventilated caging units, equipped with calibrated feeding and drinking bottles,suspended within the cages as designed at the NeurophytotherapyResearch Laboratory. Animals were maintained under 12-12 diurnal cycle. Ethical approval for the study, numbered OOU-AREC/18/VII/23-016, was obtained from the Anatomical Research Ethics committee (AREC).

\section{Experimental Design}

The details of the control and experimental groups, as well as their administered substances, dosages and respective durations as obtained in the study, are shown in Table I.

Table I: Experimental design, dosing and durations

\begin{tabular}{|c|c|c|c|c|c|}
\hline Group & $\begin{array}{l}\text { Number of } \\
\text { Mice }\end{array}$ & $\begin{array}{l}\text { Substance } \\
\text { administered }\end{array}$ & Dosage & Route of administration & Duration (Days) \\
\hline Control & 15 & Normal saline & $1 \mathrm{ml} / \mathrm{kg}$ & $\begin{array}{l}\text { Subcutaneously } \\
\text { Orally }\end{array}$ & $\begin{array}{l}\text { Concurrently for } 16 \\
\text { days } \\
\text { altogether }\end{array}$ \\
\hline HML & 15 & $\begin{array}{l}\text { Harmaline } \\
\text { Normal saline }\end{array}$ & $\begin{array}{l}20 \mathrm{mg} / \mathrm{kg} \\
1 \mathrm{ml} / \mathrm{kg}\end{array}$ & $\begin{array}{l}\text { Subcutaneously } \\
\text { Orally }\end{array}$ & $\begin{array}{l}\text { Concurrently for } 16 \\
\text { days } \\
\text { altogether }\end{array}$ \\
\hline NS & 15 & $\begin{array}{l}\text { Nigella sativa. } \\
\text { Normal saline }\end{array}$ & $1.0 \mathrm{ml} / \mathrm{kg}$ & Subcutaneously & $\begin{array}{l}\text { Concurrently for } 16 \\
\text { days } \\
\text { altogether }\end{array}$ \\
\hline \multirow[t]{2}{*}{ HNS } & 15 & Harmaline & $20 \mathrm{mg} / \mathrm{kg}$ & Subcutaneously & $\begin{array}{l}\text { Concurrently for } 16 \\
\text { days } \\
\text { altogether }\end{array}$ \\
\hline & & Nigella sativa & $\begin{array}{l}1.0 \mathrm{ml} / \mathrm{kg} \\
\text { Nigella sativa }\end{array}$ & Orally & \\
\hline \multirow[t]{2}{*}{$\mathrm{NSH}$} & 15 & Nigella sativa & $1.0 \mathrm{ml} / \mathrm{kg}$ & Orally & Initial 16 days \\
\hline & & Harmaline & $20 \mathrm{mg} / \mathrm{kg}$ & Subcutaneously & $\begin{array}{l}\text { Another } 16 \text { days } \\
\text { following Nigella } \\
\text { sativa regimen }\end{array}$ \\
\hline
\end{tabular}

Measurement of Body Weight

The body weights of the animals were measured at the commencement and the end of the study, using a digital weighing balance $\left(\mathrm{KERRO}^{\circledR}\right.$, 2016; 0.1g accuracy).

\section{Olfactory sensitivity and discrimination test}

The Buried food test was employed as a neurobehavioral test to assess olfactory sensitivity and discrimination in the mice across groups. The test measures how fast a starved mouse can find a cookie or flavour buried within the behavioural paradigm, and also how fast it can discriminate between an earlier recognised flavour and a novel (second) one. For this study, the strawberry and banana flavours were used. The buried food test comprised of three phases, namely 'habituation', 'familiarisation' and 'test' phases. Each of these phases lasted five minutes. 
During the habituation phase, each mouse was introduced to the empty paradigm, devoid of the flavours, simply for habituation to the environment. It was, thereafter, removed from the environment. The familiarisation phase consisted of introducing the animal to the paradigm while the first flavour (strawberry) had already been buried within the beddings (1$2 \mathrm{~cm}$ deep). The time it took the starved mouse to uncover the flavour was recorded as the measure of olfactory sensitivity. The mouse was left afterwards to familiarize with this uncovered flavour for five minutes, after which it was removed from the paradigm.

During the test phase, the mouse was introduced into the paradigm, with both the familiar (strawberry) and the novel (banana) flavours already buried. The time it took the mouse to uncover the novel flavour, different from the familiar one was recorded as the measure of olfactory discrimination.

Following each session of mouse exposure to the paradigms, cage beddings were replaced and the whole paradigm cleaned with $70 \%$ alcohol, to preclude olfactory cues and bias for the subsequent mouse.

\section{Sacrifice}

Following administration and neurobehavioralassays, animals were weighed and sacrificed through cervical dislocation. Thereafter, olfactory bulbs excised from the animals in each group were randomised into two categories.Some of these were preserved in $10 \%$ Formal saline and were processed for histologicalillustrations using the haematoxylin and eosin (H\&E) stain, while others were homogenised in $0.1 \mathrm{M}$ phosphate buffer saline (PBS), centrifuged and then taken through UV
Spectrophotometry for quantification of olfactory bulb glutamate and dopamine.

\section{Statistical analysis}

The data acquired were expressed as Mean ( \pm Standard Error of Mean) and were analysed with One-Way Analysis of Variance (ANOVA) using the GraphPad Prism (version 7.0) software. Statistical significance was set at $\mathrm{P}<0.05$.

\section{Results}

Neurobehavioural Assay

Figure 1 shows the olfactory sensitivity test that was conducted across all groups. The administration of harmaline led to insensitivity on the mice compared to the control group. Concurrent treatment with Nigella sativa resulted in higher olfactory sensitivity compared to the HML group.Pre-treatment with Nigella sativa also improved the olfactory sensitivity in the mice.

Figure 2 shows the olfactory discrimination of the animals across all groups. The HML mice discriminated both flavours earlier than the control mice, butpre-administration with Nigella sativa oil made the NSH mice discriminate better than HML. However, the NS group discriminated best. Concurrent administration of Nigella sativa with harmaline did not result in any appreciable difference in the discriminating abilities of the NSH and HML mice. 


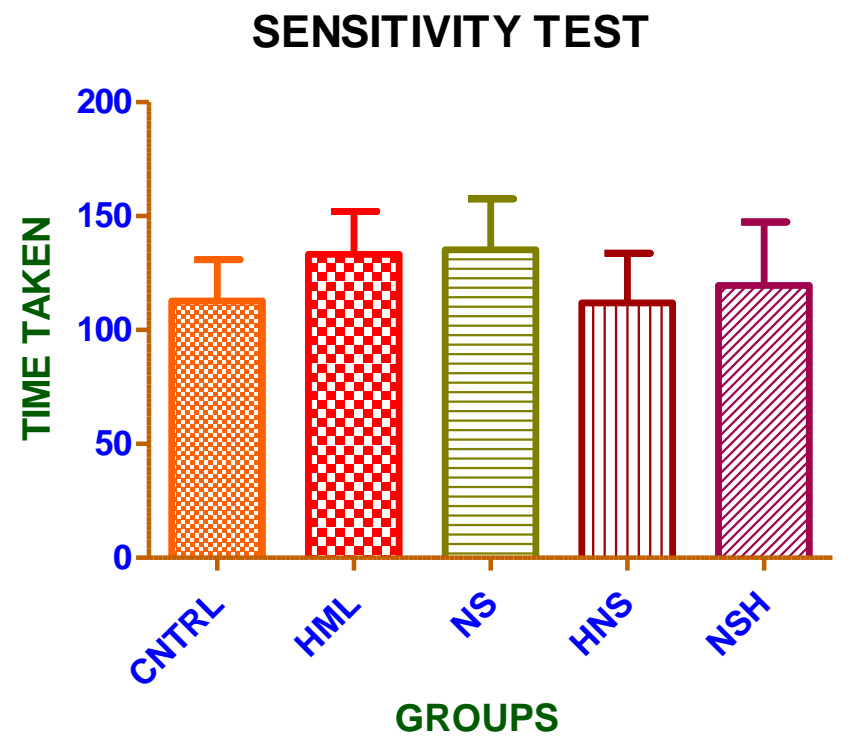

Figure 1: Olfactory sensitivity assay, showing the time spent by each group of animals to discover the familiar flavour in a paradigm containing only the familiar flavour.

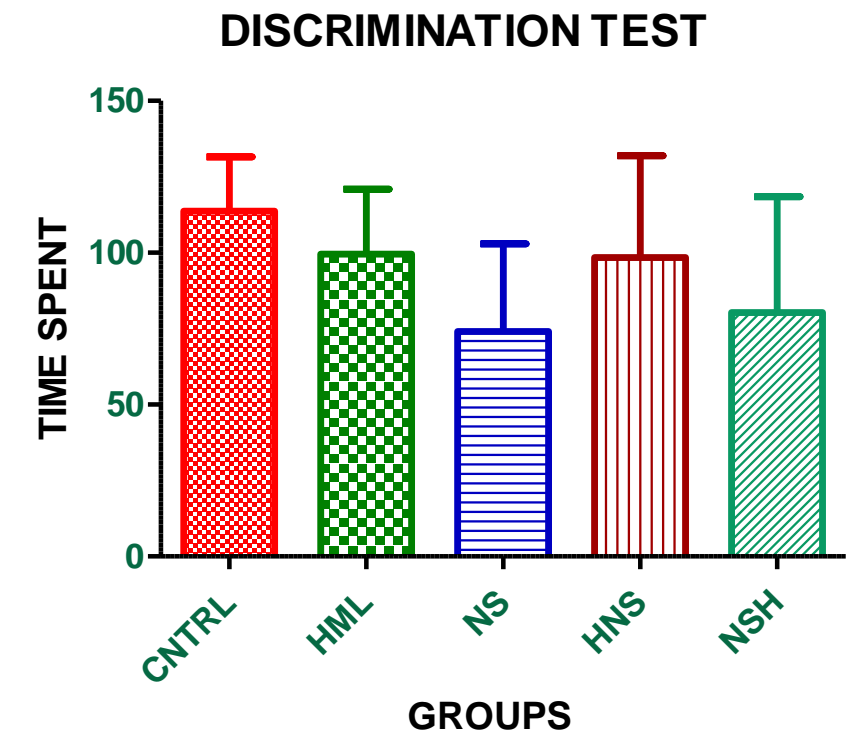

Figure 2: Olfactory discrimination assay, showing the time spent by each group of animals to discover the novel flavour in a paradigm containing both the novel and the familiar flavours

Figure 3 shows the weight difference across all groups, with the control grouprecording the highest body weight increment. The administration of harmaline led to a higher body weight increase than NS. The concurrent 
treatment group showed the least body weight gain.

Figure 4 shows the relative brain weight of all animals across all groups. The administration of harmaline led to a higher brain weight compared to the control, however, this value was higher in all three groups which received Nigella sativa oil.

Figure 5 shows the olfactory glutamate level across all groups. A higher glutamate level was recorded in all experimental groups compared to the control group. The NS group had the highest levels, while there was not much difference between the levels in the HML, HNS and NSH groups.

Figure 6 shows the olfactory bulb dopamine levels across the mice groups, in which the administration of NS resulted in the highest dopamine level. While the administration of harmaline led to a slightly higher level of dopamine than the control, the HML, HNS and NSH levels were not significantly different.

Figure 7 shows the average volume of water consumed across all groups per day. The administrationof harmaline led to a reduction in water intake compared to the control group, while the group administered with NS took more water compared with all other groups. Concurrent administration of harmaline with NS led to a similar value with the HML group, even though they consumed slightly but insignificantly higher volume.

Figure 8 shows the amount of feed consumed across all groups. The HML group consumed the least, while the NS group consumed slightly more than the HML and control groups. However, concurrent and pre-treatment of NS led to higher feed consumption.

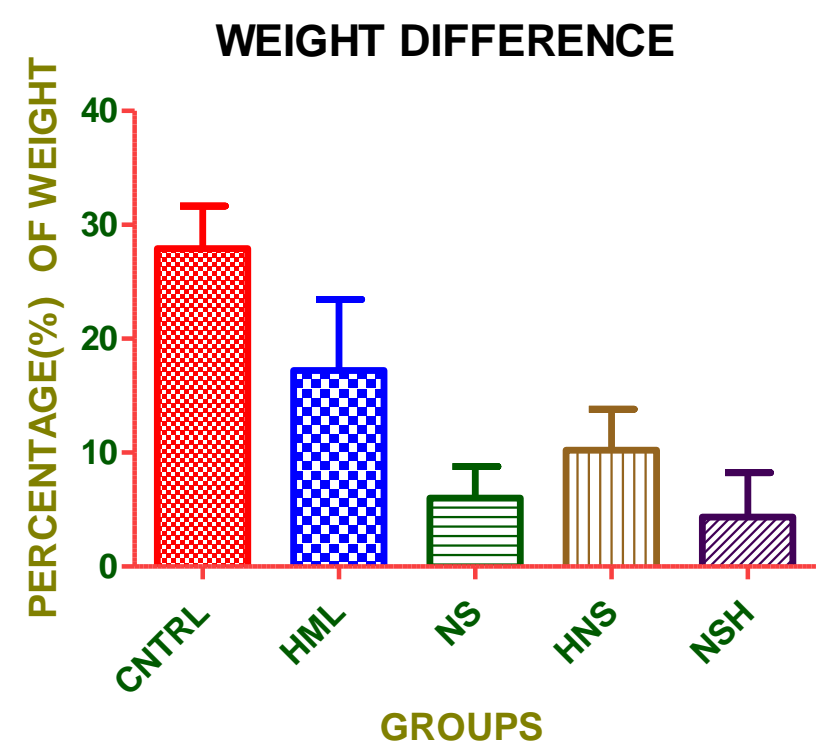

Figure 1: Bodyweight differences across all groups 


\section{RELATIVE BRAIN WEIGHT}

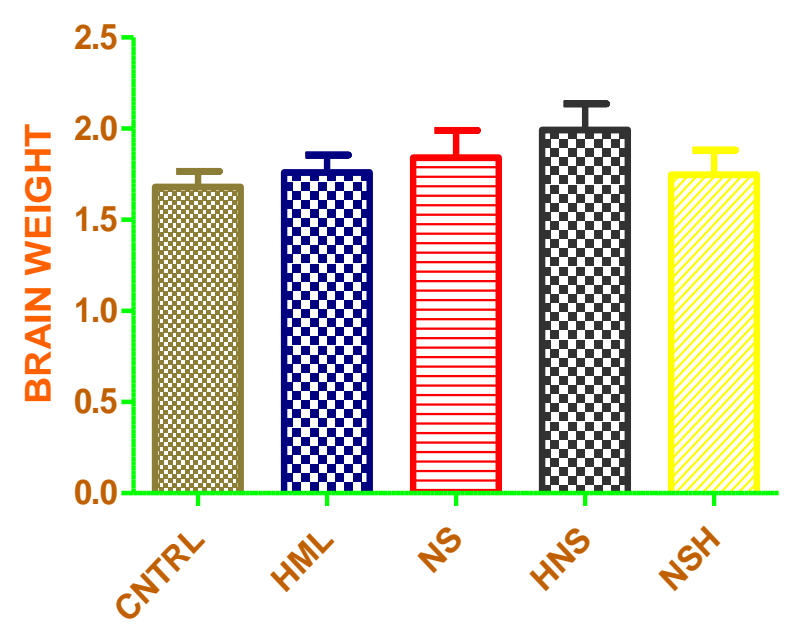

GROUPS

Figure 2: Relative brain weights of animals across all groups

\section{GLUTAMATE LEVEL}

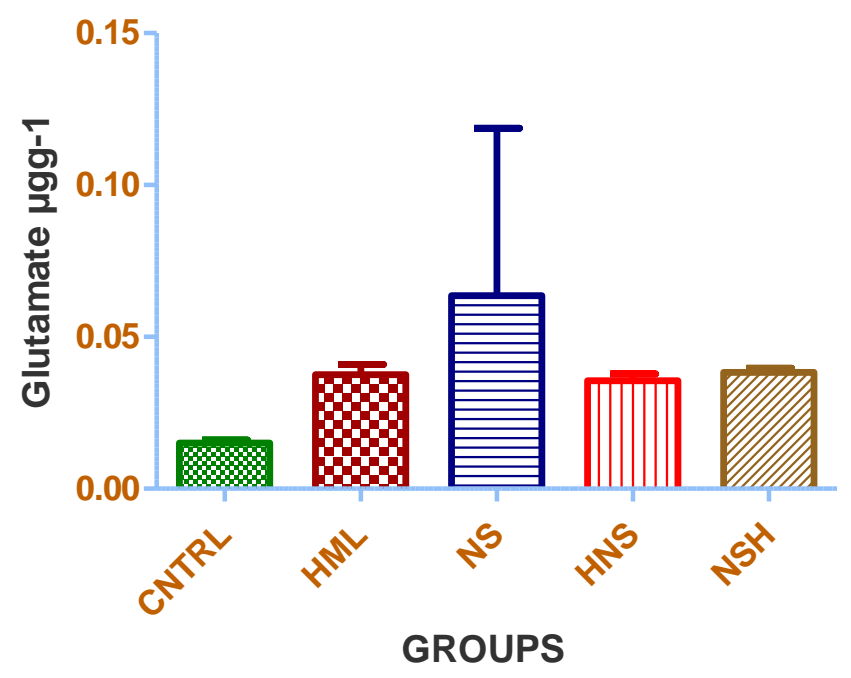

Figure 3: Glutamate level in the olfactory bulbs of mice across all groups

Histological Assay

Plate 1 shows the histoarchitecture of the olfactory bulb across all groups, in addition to the neuronal densities and average sizes. The HML group, treated with harmaline showed the highest neuronal density. The NS group also demonstrated higher neuronal density than the control group, but not to the level recorded in the HML group. The administration of NS again led to a higher average neuronal size than the 
HML group. However, concurrent administration of NS and harmaline resulted in similar neuronal sizes between the HNS and HML groups.

\section{DOPAMINE LEVEL}

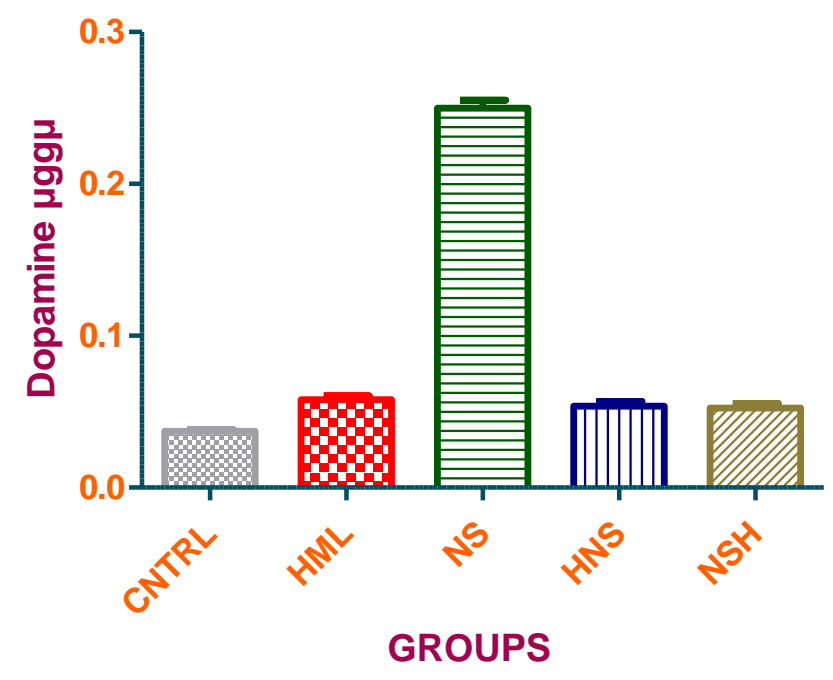

Figure 4: Dopamine level in the olfactory bulbs of mice across all groups

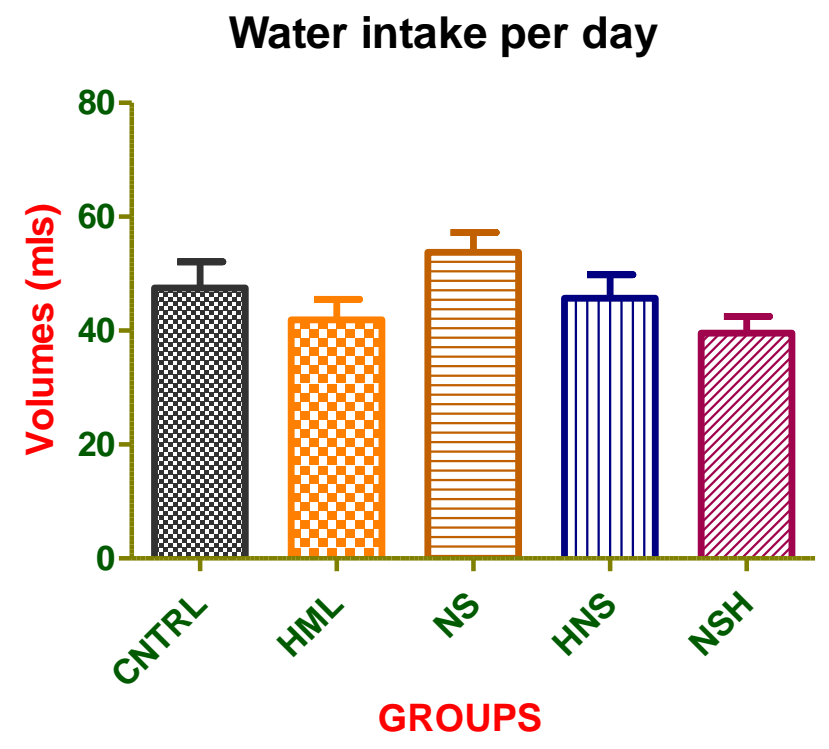

Figure 5: Average daily water intake by animals 


\section{FEEDING TROUGH}

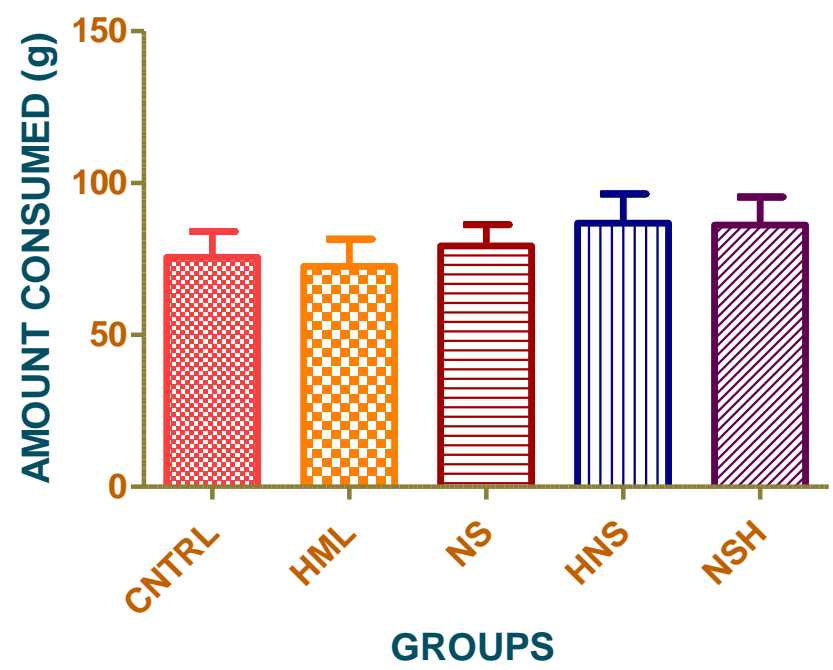

Figure 6: Average quantity of food consumed by animals per day

\section{Discussion}

Olfactory sensitivity and discrimination tests were employed to assay the animals' odour sensitivity as well as their ability to identify and differentiate between olfactory cues. This study revealed that the administration of Nigella sativa enabled the NS group to discriminate better than all the other groups.This finding corroborates earlier reports, ${ }^{[10]}$ in which the mice showed higher sensitivity in the presence of a novel object and also further validation of the neuroprotective and therapeutic potentials of Nigella sativa. [11]

The relative brain weight also referred to as brain-to-body mass ratio or brain-to-body weight ratio, is a hypothetical estimate of the intelligence of an animal, although fairly so in many cases. ${ }^{[12]}$ The administration of harmaline thus led to an increase in the relative brain weight. It was also realized that the mice induced with harmaline and treated concurrently with Nigella sativa also experienced increased in relative brain weight. This observation implies that both Nigella sativa and the administration of harmaline increase the brain weight of animals.

Harmaline use was also associated with increased body weight in mice that were inflicted with ET (HML) but pre-treatment with Nigella sativa as seen in the NSH group prevented that level of weight increase. Nigella sativaalso limited the level of weight gain in all NS-treated micein corroboration of the earlier reports, which established the weight limiting effects of NS. [13]

The administration of NS increased water intake by the animals in corroboration of earlier reports, [14] while the administration of harmaline reduced the intake of water when compared with the control group. The NS group also consumed more food than the control and HML groups, while the pre-treated and the group with concurrent administration consumed much more feeds than others. This suggests the appetite boosting potentials of 
Nigella sativa which in contrast to an earlier report. [15] This also suggests the inverse proportionality between the weight limiting effect and the appetite boosting tendency of Nigella sativa.

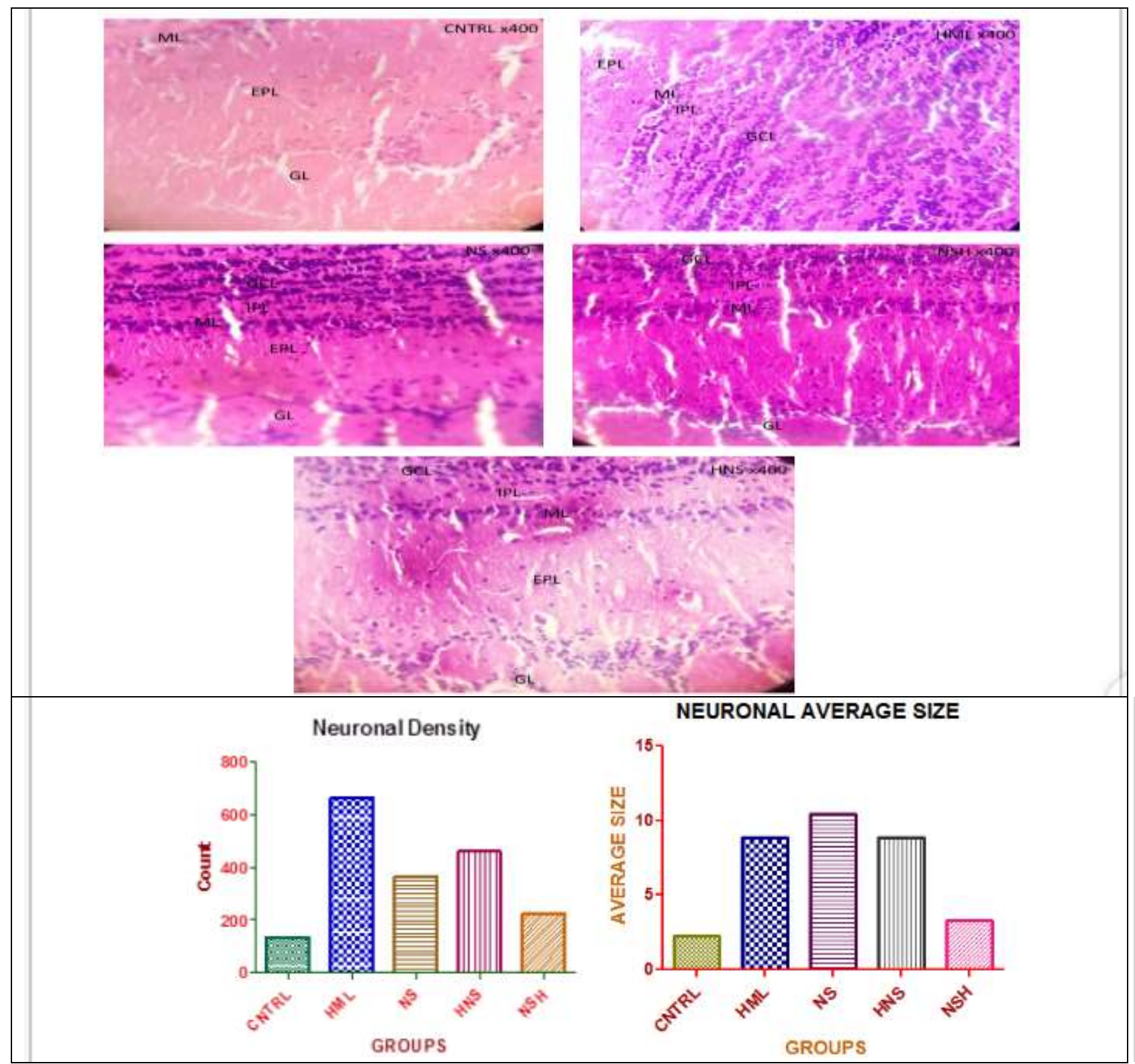

Plate 1: Histoarchitecture of the olfactory bulb $\times 400$ magnification across all groups using $\mathrm{H}$ \& $\mathrm{E}$ stain in addition to graphical representations of neuronal densities and average neuronal sizes. GCL - Granular cell layer; IPL Internal plexiform layer; MCL - Mitral Cell Layer; EPL -External Plexiform Layer; GL - Glomerular Layer.

Even though harmaline was administered in the right route and dosage, a tremor was not elicited in the mice so exposed unlike in earlier reports. ${ }^{[16]}$ However, it rather resulted in a deficiency in olfactory sensitivity and discriminative behaviour. This observation requires a further appraisal of the brand of harmaline utilised for this research.The animals treated with harmaline showed the highest neuronal density, while the ones treated with Nigella sativa 
showed the highest average neuronal size. The average neuronal size in the group with concurrent administration was also high, but it was same with the HML group. Dopamine is a neurotransmitter released by nerve cells to send signals to other nerve cells serving as a neuromodulator. Harmaline reduced the mice olfactory dopamine levels despite pre-treatment or co-administration of Nigella sativa. This finding corroborates some earlier findings. [17][18] Meanwhile, the administration of Nigella sativa alone led to an increasein the dopamine level in the olfactory bulbs of the NS group: a finding the precedent of which is yet to be identified in the literature.

\section{Conclusion}

In this study, the administration of harmaline did not induce tremor or any significant histological nor neurochemical deficit in the olfactory bulbs of the mice. However, it resulted in behavioural deficits such as olfactory insensitivity and indiscrimination, both of which were prevented and ameliorated by Nigella sativa oil. Furthermore, Nigella sativa oil showed medicinal potentials beyond the control and harmaline-treated mice with distinct histological, neurochemical and behavioural patterns. Therefore, oral administration of Nigella sativa oil ameliorated olfactory deficits induced by harmaline. While the use of Nigella sativa oil is shown by the study as a promising therapeutic agent for the management of olfactory deficiencies in essential tremor, further histochemical assessments are recommended through the use of dendritic and Nissl markers for further histomorphological description. The study shall be repeated in female BALB/c mice for validation, after which translational clinical trials shall also be initiated to drive home these findings for possible therapy in human essential tremor. Further studies are also required to appraise the potency of harmaline as a model of essential tremor behaviourally.

Authors' Contributions: FR conceived and designed the study. FR, JS, OO1, TN, OO2 and ME participated in data collection and analysis. FR and JS drafted the manuscript and all the authors reviewed the draft and approved the final version of the manuscript.

Conflicts of interest: None.

Funding: Self-funded.

Publication History: Submitted 08 December 2019; Accepted 31 March 2020.

\section{References}

1. Pahwa R, Dhall R, Ostrem J, Gwinn R, Lyons $\mathrm{K}$, Ro $\mathrm{S}$, et al. An Acute Randomized Controlled Trial of Noninvasive Peripheral Nerve Stimulation in Essential Tremor. Neuromodulation. 2019; 22: 537-545.

2. Agarwal S, Biagioni MC. Essential Tremor. In: StatPearls [Internet]. Treasure Island (FL): StatPearls Publishing; 2019 [cited 2020 Jan 25].

3. Brogley JE. DaTQUANT: The Future of Diagnosing Parkinson Disease. J Nucl Med Technol 2019; 47: 21-26.

4. Louis ED, Jurewicz EC. Olfaction in essential tremor patients with and without isolated rest tremor. Mov Disord Off J Mov Disord Soc 2003; 18: 1387-1389.

5. Quagliato LB, Viana MA, Quagliato EMAB, Simis S. Olfaction and essential tremor. Arq Neuropsiquiatr 2009; 67: 21-24.

6. Cheng MM, Tang G, Kuo S-H. HarmalineInduced Tremor in Mice: Videotape Documentation and Open Questions About the Model. Tremor Hyperkinetic Mov [Internet]. 2013 ; 3. Available from: https://www.ncbi.nlm.nih.gov/pmc/article s/PMC3863988/

7. Benito-León J. Essential Tremor: One of the Most Common Neurodegenerative Diseases? Neuroepidemiol 2011; 36: 77-78. 
8. Louis ED, Rios E, Pellegrino KM, Jiang W, Factor-Litvak P, Zheng W. Higher Blood Harmane (1-Methyl-9h-Pyrido[3,4-B]Indole) Concentrations Correlate With Lower Olfactory Scores In Essential Tremor. Neurotoxicol 2008; 29: 460-465.

9. Forouzanfar F, Bazzaz BSF, Hosseinzadeh H. Black cumin (Nigella sativa) and its constituent (thymoquinone): a review on antimicrobial effects. Iran J Basic Med Sci. 2014; 17: 929-938.

10. Bermejo-Pareja F, Puertas-Martín V. Cognitive Features of Essential Tremor: A Review of the Clinical Aspects and Possible Mechanistic Underpinnings. Tremor Hyperkinetic Mov [Internet]. 2012; 2. Available from: https://www.ncbi.nlm.nih.gov/pmc/article s/PMC3572680/

11. Abdel-Zaher AO, Abdel-Rahman MS, Elwasei FM. Protective effect of Nigella sativa oil against tramadol-induced tolerance and dependence in mice: role of nitric oxide and oxidative stress. Neurotoxicol 2011; 32: 725-733.

12. Cairó O. External Measures of Cognition. Front Hum Neurosci [Internet]. 2011; 5. Available from: https://www.ncbi.nlm.nih.gov/pmc/article s/PMC3207484/

13. Sahebkar A, Soranna D, Liu X, Thomopoulos C, Simental-Mendia LE, Derosa G, et al. A systematic review and meta-analysis of randomized controlled trials investigating the effects of supplementation with Nigella sativa (black seed) on blood pressure. J Hypertens [Internet]. 2016; Available at: https://moh-

it.pure.elsevier.com/en/publications/asystematic-review-and-meta-analysis-ofrandomized-controlled-tr

14. Nigella Seeds: What the Heck Do I Do with Those? | Arts \& Culture | Smithsonian Magazine. Available from: https://www.smithsonianmag.com/artsculture/nigella-seeds-what-the-heck-do-ido-with-those-29298883/?no-ist

15. Bano F, Wajeeh M, Baig N, Naz H, Akhtar N. Antiobesity, antihyperlipidemic and hypoglycemic effects of the aqueous extract of Nigella Sativa seeds (Kalongi). Pak J BioChem Mol Bio 2009; 42: 136-140.

16. Lotsof H. Method of Treating Chemical Dependency Using $\beta$-Carboline Alkaloids, Derivatives and Salts thereof. 5591738, 1997.

17. Martin FC, Thu Le A, Handforth A. Harmaline-induced tremor as a potential preclinical screening method for essential tremor medications. Mov Disord. 2005; 20: 298-305.

18. Ondo W. Essential Tremor: What We Can Learn from Current Pharmacotherapy. Tremor Hyperkinetic Mov [Internet]. 2016; 6. Available from: https://www.ncbi.nlm.nih.gov/pmc/article s/PMC4790207/ 